\title{
Analysis on Influencing Factors of Farmers Involving in Rural Social Endowment Insurance
}

\section{--Take Huiping Town, Qidong City, Jiangsu Province as Example}

\author{
Kai-xia Wang \\ School of Economic Administration, Sichuan Agricultural University \\ Ya'an 625014, China
}

Tel: 86-131-9471-0255Ｅ-mail: daxiangwuxing1986@hotmail.com

Hong-an Xiao

School of Economic Administration, Sichuan Agricultural University

Ya'an 625014, China

Tel: 86-136-0826-9969Ｅ-mail: honganxiao@163.com

Wen-xiu Zhang (Corresponding author)

School of Economic Administration, Sichuan Agricultural University

Ya' an 625014, China

Tel: 86-133-0816-1528Ｅ-mail: cndzwx@163.com

\begin{abstract}
Based on the survey data of 202 farmers which are in the town of Huiping, Qidong city, Jiangsu Province, China, the article empirically analyzes the factors which impact farmers involving in rural social endowment insurance by Logistic model. The research shows that farmers insured or not is affected by education level of farmers, professional situation, land area, age, special experience, family size and acceptable level of payment. Therefore, this article proposes some policy recommendations, such as strengthening the support for rural education, increasing the income of the farmers and so on.
\end{abstract}

Keywords: Rural social endowment insurance, Influencing factors, Logistic model

\section{Introduction}

Since 1986, Ministry of Civil Affairs has begun to explore the establishment of rural social endowment insurance system. And in 1991, there was a pilot in the county of Muping, Yantai City, Shandong Province, which achieved success. Then in 1992, on the basis of pilot experience, Ministry of Civil Affairs drew up and issued a "basic program of county-level rural social endowment insurance (Trial)", after this the program gradually extended in the conditional country. Although the pilot work of rural social endowment insurance has achieved some remarkable effects in the nearly two decades of practice, the effects were not ideal; especially in recent years, there was a phenomenon of decline in the proportion of participants in some areas.

In China, the ratio of the aged in rural areas is increasing rapidly. According to the fifth census data which showed that old people over 60 were more than $10 \%$ of the total rural population, which was 1.24 percentage points higher than the city'. Therefore, China is entering a typical aging society. And the increase in the proportion of elderly people makes the support for the elderly a burden for the modern family. So the demands of pension are huge for old-age farmers who urgently need a new approach to replace the traditional way of pension, and endowment insurance is generated under the new demand.

In view of the importance of construction about rural social endowment insurance, many scholars have done a lot of research from different angles.

Research on the development of rural social endowment insurance: Rural social endowment insurance has achieved a certain degree of development, especially in affluent areas, and the number of farmers insured was 
more than half, but the overall level of China's rural social endowment insurance was not high, especially in less developed areas, because many farmers did not understand the policy of rural social endowment insurance, or vaguely understood the policy (Li Xin-ping \& Tang Zhi-liang, 2000). Rural social endowment insurance has presented a shrinking trend in recent years (Wu Ruo-feng, Chen Chen \& Fu Zhong-yu). The situation of rural social security was not optimistic and the overall ratio of farmers insured was only about $15 \%$ (Lv Ji-ming, 2005).

Research on the problems of rural social endowment insurance: Rural social endowment insurance system itself was lack of properties of society, welfare and mutual aid, which did not adapt to the changes of our society, and the level of security was low, the system of security was unstable, the form of premium investment was single, the appreciation of the funds was difficult, the source of premium funding was instability, and rural social endowment insurance was lack of adequate and reliable financial security (Gong Cun-zi,2007). China's current rural social endowment insurance was against the principle of social justice, and had the following problems such as that the construction of legal system was lags behind, the management and supervision were ineffective and some of the workers had low quality (Li Ya-wei, 2006; Zhong Jin \& Xie Ping, 2006). The attention of rural social endowment insurance our country paid was insufficient, which led to the system of rural social endowment insurance showing the dual characteristics (Li Yong-cheng, 2006).

Research on the strategies of promoting the development of rural social endowment insurance: We should strengthen the construction of legal system about rural social endowment insurance (Xu Xiao-qing, 2007); we should solve problems through various channels of financing and improve the system of fund management (Zhang Jin-feng, Yang Jian \& Yan Sheng-wen, 2008); we should establish a comprehensive or specialized social security institution, and train talents of social security at different levels in institutions of higher learning (Zhong Jin \& Xie Ping, 2006); based on the dual characteristics of rural social endowment insurance, we could create co-ordinate system of rural social endowment insurance (Mu Chao \& Tao Lin, 2008). Some scholars believed that government was the main responsibility of social security, and commitment to rural social endowment insurance was its responsibility, so clearing the responsibility of government in rural social endowment insurance would be in favor of the running of the system about rural endowment insurance (Liu Dan \& Zhou Jing-ling, 2007).

Since many scholars have done some research on the status, problems and countermeasures of rural social endowment insurance which plays an important role in the promotion of rural social endowment insurance. However from the current studies, there was just a little of research on the analysis on influencing factors of farmers involving in rural social endowment insurance.

The main purpose of this article is to explore a number of measures for promoting the farmers' active participation in rural social endowment insurance by the analysis on influencing factors of farmers in the town of Huiping involving in rural social endowment insurance.

\section{Data sources and sample descriptive statistics}

\subsection{Data sources}

The sample data is from the survey of farmers in the town of Huiping involving in rural social endowment insurance which is done by the author from January to February in 2009, and the survey includes farmers' personal characteristics, family characteristics and other characteristics. The survey is taken by random sampling method, and the author investigates six villages such as Hewan Village, Yongsheng Village, Haihong Village, Hongdong Village, Hongxi Village and Changle Village. A total of 215 questionnaires are distributed, including 212 questionnaires recovered, of which 202 questionnaires are valid, so the efficiency of the questionnaires is $95.28 \%$.

\subsection{Implementation of the rural social endowment insurance in the survey area}

The survey shows that 72 farmers participate in rural social endowment insurance, which accounted for 35.64\%, comparing with 130 farmers uninsured, which accounted for $64.36 \%$, and from the above analysis we could see that the proportion of involving in rural social endowment insurance is not high.

Through the investigation, we find that $95.01 \%$ of the farmers are aware of rural social endowment insurance which shows that the cognitive scale of rural social endowment insurance is quite high. There are 68 people who understand the policy of rural social endowment insurance quite well which shows that the propaganda of the policy is quite in place, as table 1 shows.

By comparing the contents of table 1 , we can see that the ratio of farmers uninsured who understand the policy is only $13.85 \%$, while the ratio of the insured who are well aware of the policy is $69.44 \%$. 
The ways of farmers' understanding rural social endowment insurance are televisions, the propaganda of village cadres, professional organizations, and friends or families, as table 2 shows. The study finds that the main way for understanding the rural social endowment insurance for farmers is the propaganda of village cadres.

\subsection{Description of basic characteristics for farmers}

Drawing on relevant research, the article breaks the influencing factors of farmers involving in rural social endowment insurance down into personal characteristics, family characteristics and other characteristics. And personal characteristics include age, education level, special experience, and professional situation; family characteristics include family size, number of children and income; other characteristics include the land area and an acceptable level of payment.

\subsubsection{Personal characteristics}

The age can reflect the differences between generations, so for the security of old-age, farmers of different ages have different senses of urgency; education level is relevant with personal ability, psychological quality and sense of self-protection, etc, which will affect the awareness of rural social endowment insurance, and then will affect the farmers' involving in rural social endowment insurance; experience is related to the level of personal knowledge and abilities, so different experiences may affect the farmers' involving in rural social endowment insurance; professional situation may also affect the way of the choice of individual endowment in varying degrees. And these have been verified by relevant research at home and abroad (Kong Xiang-zhi \& Tu Sheng-wei, 2007).

(1) Age

There are 102 men in the total number of the survey, accounting for $50.50 \%$ of the total sample comparing with 100 females, accounting for $49.50 \%$. Comparison of age distribution for uninsured and insured is in table 3 .

Table 3 shows that there are 18 farmers uninsured between the ages of $18-30$ years old, accounting for $13.85 \%$ in the proportion of the uninsured, while 4 people uninsured, accounting for $5.56 \%$ in the percentage of the insured. The study shows that age is a factor for farmers in whether insured or not.

(2) Education level

There are 60 people in the level of Primary School or below in the total number of the survey, accounting for $29.70 \%$ of the total sample, 82 people in the level of Junior Middle School, accounting for $40.59 \%$, 52 people in the level of High School, accounting for $25.74 \%, 6$ people in the level of Junior College, accounting for 2.97\%, and 2 people in the level of Undergraduate or above, accounting for $0.99 \%$. Comparison of education level for the uninsured and insured is in table 4 . Among the uninsured, there are $80.00 \%$ of the farmers are in the level of Junior Middle School or below, while for the insured, there are $47.23 \%$ of the farmers are in the level of High School or above.

(3) Special experience

There are102 people who have special experiences in the total number of the survey, such as serving as village cadres, working outside and so on, accounting for $50.50 \%$ of the total sample, comparing with 100 people who don't have special experiences, accounting for $49.50 \%$. Among the farmers insured, there are $58.33 \%$ of the farmers have special experiences, only $41.67 \%$ of the farmers don't have special experiences, which shows that farmers who have special experiences are more inclined to participate in rural social endowment insurance.

(4) Professional situation

There are 44 people who are traditional farmers, accounting for $21.78 \%$ of the total sample; 2 people who are agricultural workers, accounting for $0.99 \% ; 70$ people who are semi-industrial and semi-agricultural workers, accounting for $34.65 \%$; 44 people who are workers, accounting for $21.78 \% ; 8$ people who are managers, accounting for $3.96 \%$; 34 people who engage in other occupations, accounting for $16.83 \%$.

Occupation such as traditional farmer, agricultural worker, semi-industrial and semi-agricultural worker, and other profession has less impact on farmers' insured or not, while occupation such as manager and other occupation promote farmers to attend rural social endowment insurance. Among the farmers uninsured, the ratio of engaging in management and other occupations is only $15.38 \%$; while for the insured, the ratio is $30.56 \%$.

\subsubsection{Family characteristics}

Family characteristics are important reasons for differences on personal thoughts and behaviors (Lin Hai-xia, 2001). The family size relates to the possibility of household income transferring between generations and may affect the situation of farmers' insured or not; the number of children in the family relates to the ability of supporting the elderly, and if farmers have more children, the expectations of them are greater to rely on their 
children when they are old; Family income may also become an important factor for farmers whether insured or not (Kong Xiang-zhi \& Tu Sheng-wei, 2007).

(1) Family size and the number of children

In the region, there are mainly 3 people in the family, accounting for $59.41 \%$ of the total sample, and followed by 2 and 4 people, both accounting for $15.84 \%$. The average number of children in the family is 1.30 , and the average number of children is 1.34 for the uninsured and 1.25 for the insured.

(2) Income

Most farmers' personal income is 7500 yuan per year, accounting for $31.68 \%$ of the total sample, then followed by 12500 yuan, accounting for $27.72 \%$. $61.39 \%$ of annual income about household is 20000 yuan, and $27.72 \%$ annual household income is between 10000 and 20000 yuan, only $10.89 \%$ of annual income about household is 10000 yuan or less. Annual income about household of the uninsured is 17250 yuan, comparing with 17900 yuan for the insured.

\subsubsection{Other characteristics}

It is generally believed that land area is opposite to farmers' insured or not, so the more land the farmers own, the more they don't want to join rural social endowment insurance. The reason is that when farmers are old, they can make its own land as a pension protection. The pension payment standard condition also affects the farmers' insured or not. And if the payment is too high, it will affect the enthusiasm of farmers; on the contrary, if it's too low, the ratio of the compensation is so low that can not be able to protect farmers' lives of elderly effectively.

(1) Land area

The average land area is $2.79 \mathrm{mu}$ for the insured comparing with $2.48 \mathrm{mu}$ for the uninsured. It's opposite to the general result, which shows that the land may no longer be the only option for farmers when they are old.

\section{(2) Acceptable level of payment}

Through analysis of the survey data, farmers can accept the payment level of 49.11 yuan per month, that is 589.32 yuan per year, but the payment standard of rural social endowment insurance is not less than 800 yuan in 2008 , witch is 210.68 yuan higher than the acceptable level. Analysis shows that the pension payment standard is also an influential factor for farmers whether insured or not.

\section{Model and analysis of results}

\subsection{Variable selection}

Based on the awareness of influential factors for farmers involving in rural social endowment insurance, the article breaks the independent variables of affecting farmers' insured or not into individual characteristic variables, family characteristics variables, and other characteristic variables. Description and statistical description of variables are in table 5.

\subsection{Model and calculation}

Based on the above description and analysis, we set the relationship of influencing factors for farmers involving in rural social endowment insurance as the following function form:

Farmers join rural social endowment insurance $=\mathrm{f}$ (personal characteristics variables, family characteristics variables, other characteristics of the variables, other factors) + random perturbation

For farmers, whether insured or not is difficult to directly indicate and measure by value, so in this paper, the author uses "0-1" index method to manifest farmers" insured or not, and uses "1" to indicate that farmers' participating in rural social endowment insurance; uses " 0 " to indicate farmers" not participating in rural social endowment insurance. The range of the dependent variable in the traditional regression model is between negative infinite and positive infinite, but in this study the variable values is between 0 and 1 , so the author uses Logistic regression model. Let $\mathrm{y}=1$ with probability $\mathrm{P}$, and calculate the probability of the dependent variable 1 .

$$
P=\left(y_{i}=1 \mid x_{i}, \beta\right)=F\left(-x_{i}{ }^{\prime} \beta\right)
$$

In this definition, the author uses maximum likelihood estimation, the function model is estimated as:

$$
P_{t}=F\left(\alpha+\sum_{t=1}^{m} \beta_{j} x_{i j}\right)=1 /\left[1+\exp \left(-\alpha+\sum_{t=1}^{m} \beta_{j} x_{i j}\right)\right]+e i
$$

In the formula, $P_{t}$ means the probability of farmers' joining rural social endowment insurance, $\beta_{j}$ means the regression coefficients of factors, $m$ means the number of factors affecting the probability, $x_{i j}$ is the independent 
variable, which means the influencing factor of $j, \alpha$ means regression intercept, $e_{i}$ means random perturbation.

The author substitutes the 9 variables such as age, education level, special experience, professional situation, family size, number of children, household income, land area and acceptable level of payment into Logistic model, conducting regression analysis by using SPSS13.0. The author selects the variable standard level $\mathrm{a}=0.05$, and rejects the standard level of $\mathrm{a}=0.10$. Meanwhile, uses the Odds Ratio to explain variables in the model, which is indicated by Exp (B). Exp (B) means the change of a unit for independent variables or the change of Odds Ratio relatively to the reference category.

By testing the regression equation, we know that the chi-square test value of the model is 85.1610 , and prediction accuracy reaches $71.3 \%$. The model passes the test and has statistical significance. The model results are in Table 6.

\subsection{Results analysis}

\subsubsection{The age is significant under the level of $5 \%$, and is positively correlated}

The results show that when the farmers are older, because of the fears of old lives, they are more willing to join rural social endowment insurance. As the growth of the age, and the degradation of body function, more and more farmers will consider for the future lives. To protect the basic livelihood when they are old, they will be more inclined to join rural social endowment insurance.

\subsubsection{Education level is significant under the level of $1 \%$, and is positively correlated}

The higher education level farmers have, the more easily farmers learn and understand the policies, the more open ideas they have, the more receptive to other things, the more they can quickly understand and accept rural social endowment insurance policy and they may be more willing to join rural social endowment insurance.

\subsubsection{With or without special experience is significant under the level of 5\%}

The possible reason is that farmers who have special experiences will have more open visions, so their consumption concepts and attitudes to life are different from the others', especially for farmers who are village cadres. More than $95 \%$ of them have joined rural social endowment insurance. There are three reasons for the high ratio: Firstly, they understand the policy better; secondly, they should play an exemplary role; thirdly, they can get some certain concessions when they pay.

\subsubsection{Professional situation is significant under the level of $1 \%$}

The possible reason is that the nature of occupation is different, so the attitudes of farmers to the endowment insurance are different, which makes farmers have different expectations to their lives of elderly. The results show that farmers who have tow or above occupations are more willing to join rural social endowment insurance than farmers who simply engage in agricultural production.

\subsubsection{Family size is significant under the level of 5\%, and is positively correlated}

The survey shows that $60 \%$ of households have only one child, so if the population of family is large, it means that there are more elderly people at home to need supports, which makes farmers face a heavier burden of maintenance. As this part of the farmers has personal experience of the family support, so they know the drawbacks, out of concerning about their lives of future and reducing the burden of their children, they are more willing to participate in rural social endowment insurance.

3.3.6 Land area is significant under the level of $1 \%$

Land area is positively correlated with participating in insurance, which seems different from conventional situation. There are two possible reasons: Firstly, the change of the traditional concept for farmers makes many of them be from the fetters of the land, and the land is not their only mean of livelihood, so their dependences on land are on the decline; Secondly, farmers who have more lands engage in non-farm work less, so their incomes are less than the incomes from non-farm work. In order to guarantee their elderly lives, they are more inclined to join the insurance.

\subsubsection{Level of acceptable payment is significant under the level of 5\%, and is positively correlated}

The results show that the level of acceptable payment is also one of the factors influencing farmers' insured or not. The higher the level of acceptable payment is, the more inclined to be insured; on the contrary, they may give up joining the insurance because of their economic situation.

\section{Conclusions and recommendations}

The research shows that farmers involving in rural social endowment insurance or not are affected by education 
level of farmers, professional situation, land area, age, special experience, family size and acceptable level of payment. And the impacts are from strong to weak, showing positive correlation. Number of children is not associated with the farmers' involved or not, which may be contrary to the conventional situation. It's generally believed that if farmers have more children, they may be more inclined to rely on their children when they are old, that is to say the number of children is negatively correlated with the situation of insuring or not. The main reasons are the implementation of Family Planning System and the gradual transition of farmers' ideas. 60\% of the households have only one child, to reduce the burden of their children, the farmers choose family pension less than before. The influence that how much the number of children impacts the situation of insuring or not is on the decline.

Annual income about household of farmers is not associated with the farmers' insured or not, which is contrary to the common sense, and that makes readers consider. During the investigation, the author finds that there are two reasons for farmers of higher annual incomes about household not involving in rural social endowment insurance: Firstly, they worry about the instability of the policy on rural social endowment insurance; secondly, they have the expectations that the price would be rising in the future, so they would prefer to put their family earnings in banks or to purchase of state bonds.

Based on the analysis above, this paper proposes some policy recommendations. Firstly, the relevant departments should increase the policy propaganda of rural social endowment insurance. While most farmers have heard of rural social endowment insurance, but the ratio of real understanding is not high, so the focus of publicity should be recognized from the surface to the depth of understanding, which could remove the worries left behind about the instability of the policy on rural social endowment insurance.

Secondly, efforts to support rural education should be strengthened. As we know that rural education is the weak link in the whole education, but education level of farmers directly affects farmers' insurance situation. So in order to improve the cultural level of farmers, increasing the support efforts of funding and system to rural education is necessary.

Thirdly, farmers should get rid of the land-bound and free from the land, so that they could engage in the secondary industry and tertiary industry, which could improve their incomes and increase the level of paying the pension.

Fourthly, to accelerate the change of farmers' traditional concepts through education and publicity, etc. Since the "Raise children for old age" thinking is popular, the related departments should carry out educational activities, so that farmers could quickly change the concept to reduce the burden of the young families and family conflicts, which is the requirement to build our harmonious society.

Finally, policy of rural social endowment insurance should be changed with the times. Society is constantly changing, the policy should be adjusted in due course, but the adjustment must be based on the vital interests of farmers. With the continuous improvement of living standards of farmers, the continuous development of medical and health services, the longevity of farmers will also increase, therefore, the age limit for insurance should be suitably relaxed so that more farmers can enjoy their twilight years.

\section{References}

GONG, Chun-zi. (2007). Endowment insurance in rural area s of China: problems and solutions. Journal of Eastern Liaoning University (Social Sciences), 3:61-64.

HU, Hong-wei, CAI, Xia \& SHI, Jing. (2009). A research of rural effective demand for social endowment insurance-A comprehensive survey based on the willingness and payment capacity of farmers. Economic Survey, 6:59-63.

KONG, Xiang-zhi \& TU, Sheng-wei. (2007). Analysis on the farmers' desire for old-age support at the present stage-Based on sample survey in Yong-an, Shaowu and Guangze. Journal of Renmin University of China, 3:71-77.

LI, Xin-ping \& TANG, Zhi-liang. (2000). The status and reform of rural endowment insurance. Economic Forum, 21:13-14.

LI, Ya-wei. (2006). Exploration of problems about rural endowment insurance. Contemporary Manager, 21:1639-1640.

LI, Yong-cheng. (2006). A research based on the plight of rural endowment insurance and the solution. Finance and Economy, 1: 49-51.

LIN, Hai-xia. (2001). The study on elderly-security in rural areas of middle and western China. Master Thesis of 
Huazhong Agricultural University, March 2001.

LIU, Dan \& ZHOU, Jing-lin. (2007). Rural endowment insurance of China under the construction of new countryside. Journal of Hubei University of Economics (Humanities and Social Sciences), 6:97-98.

LV, Ji-ming. (2005). The present situation of China's rural endowment insurance and an analysis of its development ways. Journal of Ningxia Communist Party Institute, 6:47-49.

MU, Chao \& TAO, Lin. (2008). Research of the problem of the rural endowment insurance. Rural Economy, 1:120-122.

WEI, Jian \& SONG, Wei. (2007). Countermeasures analysis on influencing factors of farmers in our country involving in rural social endowment insurance. Theory Journal, 4:71-74.

WU, Yan-feng, CHEN, Chen \& FU, Zhong-yu. (2004). The status and countermeasures of rural endowment insurance in China. Theory Observe, 5:61-62.

$\mathrm{XU}$, Xiao-qing. (2007). Problem analysis of endowment insurance of rural areas in Beijing and countermeasures. Journal of Beijing Vocational College of Labor and Social Security, 3:3-6.

ZHANG, Jing-feng, YANG, Jian \& YAN Sheng-wen. (2008). The problems and development strategies in the construction of rural endowment insurance. Journal of Party and Government Officials, 2:59-60.

ZHONG, Jin \& XIE, Ping. (2006). On the problem and solution of rural endowment insurance in our country. Journal of East China Jiaotong University, 3:41-43.

Table 1. Statistics about the level of awareness of pension policy (People, \%)

\begin{tabular}{|c|c|c|c|c|}
\hline \multirow{2}{*}{ Level of awareness } & \multicolumn{2}{|c|}{ Farmers uninsured } & \multicolumn{2}{c|}{ Farmers insured } \\
\cline { 2 - 5 } & Number of farmers & Proportion & Number of farmers & Proportion \\
\hline Know and understand & 18 & 13.85 & 50 & 69.44 \\
\hline Know but not understand & 104 & 80.00 & 20 & 27.78 \\
\hline Unknown & 8 & 6.15 & 2 & 2.78 \\
\hline
\end{tabular}

Data Source: Calculated according to the data processing of the survey

Table 2. Statistics about the understanding way of endowment insurance policy (People, \%)

\begin{tabular}{|c|c|c|c|c|}
\hline \multirow{2}{*}{ Way of understanding } & \multicolumn{2}{|c|}{ Farmers uninsured } & \multicolumn{2}{c|}{ Farmers insured } \\
\cline { 2 - 5 } & Number of farmers & Proportion & Number of farmers & Proportion \\
\hline Television & 4 & 3.08 & 4 & 5.56 \\
\hline Propaganda from village cadres & 98 & 75.38 & 48 & 66.67 \\
\hline Propaganda from professional organizations & 6 & 4.62 & 16 & 22.22 \\
\hline Propaganda from friends and families & 22 & 16.92 & 4 & 5.56 \\
\hline
\end{tabular}

Data Source: Calculated according to the data processing of the survey

Table 3. Statistics of age distribution (People, \%)

\begin{tabular}{|c|c|c|c|c|c|c|c|c|}
\hline \multirow{2}{*}{ Stage of age } & \multicolumn{2}{|c|}{$18-30$} & \multicolumn{2}{c|}{$30-45$} & \multicolumn{2}{c|}{$45-60$} & \multicolumn{2}{c|}{60 and above } \\
\cline { 2 - 9 } & $\begin{array}{c}\text { Number } \\
\text { of farmers }\end{array}$ & Proportion & $\begin{array}{c}\text { Number } \\
\text { of farmers }\end{array}$ & Proportion & $\begin{array}{c}\text { Number } \\
\text { of farmers }\end{array}$ & Proportion & $\begin{array}{c}\text { Number } \\
\text { of farmers }\end{array}$ & Proportion \\
\hline Total survey & 22 & 10.89 & 56 & 27.72 & 104 & 51.49 & 20 & 9.90 \\
\hline Farmers uninsured & 18 & 13.85 & 26 & 20.00 & 72 & 55.38 & 14 & 10.77 \\
\hline Farmers insured & 4 & 5.56 & 30 & 41.67 & 32 & 44.44 & 6 & 8.33 \\
\hline
\end{tabular}

Data Source: Calculated according to the data processing of the survey

Table 4. Statistics of education level (People, \%)

\begin{tabular}{|c|c|c|c|c|}
\hline \multirow{2}{*}{ Education level } & \multicolumn{2}{|c|}{ Farmers uninsured } & \multicolumn{2}{c|}{ Farmers insured } \\
\cline { 2 - 5 } & Number of farmers & Proportion & Number of farmers & Proportion \\
\hline Primary School and below & 48 & 36.92 & 12 & 16.67 \\
\hline Junior High School & 56 & 43.08 & 26 & 36.11 \\
\hline High School & 22 & 16.92 & 30 & 41.67 \\
\hline Junior College & 2 & 1.54 & 4 & 5.56 \\
\hline Undergraduate and above & 2 & 1.54 & 0 & 0.00 \\
\hline
\end{tabular}

Data Source: Calculated according to the data processing of the survey 
Table 5. Description of variables and statistical description

\begin{tabular}{|c|c|c|c|c|}
\hline Variable name & Variable definition( 1 is the default value) & Average & Insured & Uninsured \\
\hline \multicolumn{5}{|l|}{ Explanatory variables: } \\
\hline \multicolumn{5}{|l|}{$\begin{array}{l}\text { Personal characteristic } \\
\text { variables: }\end{array}$} \\
\hline \multirow[t]{2}{*}{ Age } & $2=30-45$ & 2.60 & 2.56 & 2.63 \\
\hline & $3=45-60 \quad 4=60$ and above & & & \\
\hline \multirow[t]{2}{*}{ Education level: } & 1=Primary School and below $2=$ Junior High School & 2.05 & 2.36 & 1.88 \\
\hline & $\begin{array}{ll}3=\text { High School } & 4=\text { Junior College } \\
5=\text { Undergraduate and above } & \end{array}$ & & & \\
\hline Special experience & $1=$ Yes $\quad 0=$ No & 0.50 & 0.58 & 0.46 \\
\hline \multirow[t]{3}{*}{ Professional situation } & $1=$ Traditional farmers 2=Agricultural workers & 3.36 & 3.64 & 3.20 \\
\hline & $3=$ Semi-industrial and semi-agricultural workers & & & \\
\hline & 4=Workers $\quad 5=$ Managers $\quad 6=$ Others & & & \\
\hline \multicolumn{5}{|l|}{$\begin{array}{l}\text { Family characteristic } \\
\text { variables: }\end{array}$} \\
\hline Family size & & 3.17 & 3.33 & 3.08 \\
\hline \multirow[t]{2}{*}{ Number of children } & $2=2-3$ & 1.31 & 1.25 & 1.33 \\
\hline & $3=4-5 \quad 4=6$ and above & & & \\
\hline \multirow[t]{2}{*}{ Household income } & $1=5000$ yuan and below $\quad 2=5000-10000$ yuan & 3.50 & 3.58 & 3.45 \\
\hline & $4=20000$ yuan and above & & & \\
\hline \multicolumn{5}{|l|}{ Other variables: } \\
\hline \multirow[t]{2}{*}{ Land area } & $1=3 \mathrm{mu}$ or below & 1.72 & 1.86 & 1.65 \\
\hline & $4=5 \mathrm{mu}$ or above & & & \\
\hline \multirow[t]{2}{*}{$\begin{array}{c}\text { Acceptable level } \\
\text { of payment }\end{array}$} & $1=20$ yuan and below & 3.21 & 3.36 & 3.06 \\
\hline & $3=40-60$ yuan & & & \\
\hline \multicolumn{5}{|l|}{ Explained variable: } \\
\hline $\begin{array}{l}\text { Whether insured } \\
\text { or not }\end{array}$ & $0=$ Uninsured & & & \\
\hline
\end{tabular}

Data Source: Calculated according to the data processing of the survey

Table 6. Results of model estimation

\begin{tabular}{|l|l|l|l|l|l|}
\hline \multicolumn{1}{|c|}{ Explanatory variables } & \multicolumn{1}{c|}{ B } & \multicolumn{1}{c|}{ S.E. } & \multicolumn{1}{c|}{ Sig } & Exp(B) \\
\hline Personal characteristic variables: & & & & 1.385 \\
\hline Age & $0.325^{* *}$ & 0.150 & 4.684 & 0.030 & 2.087 \\
\hline Education level & $0.736^{* * *}$ & 0.113 & 42.339 & 0.000 & 1.497 \\
\hline Special experience & $0.403^{* *}$ & 0.189 & 4.576 & 0.032 & 1.183 \\
\hline Professional situation & $0.168^{* * *}$ & 0.065 & 6.720 & 0.010 & \\
\hline Family characteristic variables: & & & & & 0.017 \\
\hline Family size & $0.282^{* * *}$ & 0.118 & 5.677 & 0.392 & 0.085 \\
\hline Number of children & 0.159 & 0.186 & 0.733 & 0.766 & 1.051 \\
\hline Household income & 0.050 & 0.168 & 0.088 & & \\
\hline Other variables: & & & & 0.001 & 1.361 \\
\hline Land area & $0.308^{* * *}$ & 0.095 & 10.479 & 0.037 & 1.211 \\
\hline Acceptable level of payment & $0.191^{* * *}$ & 0.092 & 4.359 & & \\
\hline Prediction accuracy & $71.30^{*}$ & & & & \\
\hline Log-likelihood values & 704.263 & & & & \\
\hline Chi-square test value & 85.161 & & & & \\
\hline R of Nagelkerke & 0.436 & & & & \\
\hline
\end{tabular}

Remarks: ${ }^{* *}$ and $* * *$ represent the significant level of $5 \%$ and $1 \%$ 